\title{
Fashion Creativity in Zero-Waste Pattern Making
}

\author{
Centaury Harjani ${ }^{1}$ \\ ${ }^{1}$ Product Design/Faculty of Architecture and Design, Duta Wacana Christian University, \\ Indonesia \\ Corresponding Author's Email : centaury.h@gmail.com
}

\begin{abstract}
The Fashion industry has developed into fast fashion. Various brands and labels produce clothing every year by following mode and trends. There are more than 400 billion square meters of fabric produced into clothing in a year where 15 percent of the fabric ends up as waste. In other words, 60 billion square meters of fabric are being discarded every year. This fabric waste is one of the contributors to environmental pollution. Creating a zero-waste pattern design is one of the solutions to reduce fabric waste. The challenge is that not everyone can work on the zero waste pattern. Therefore, it requires the creation of a zero-waste pattern design that is easy to do even by ordinary people. The zero-waste pattern created in this study is simple but it can be combined with two pieces of cloth. One sheet of fabric can be created into two different clothing modes. People can be creative by using different fabric motifs combined and matched based on their creativity and tastes. As more people can make their zero-wastes clothing, it is hoped that fashion waste can be reduced. There are four creations of zero waste pattern design from two main zero-waste patterns that will be discussed in this paper.
\end{abstract}

Keywords: fashion, zero-waste, creativity, pattern

\section{INTRODUCTION}

The fashion industry is one of the creative industries that has developed not only in Indonesia but also in the world. Young designers and creative industry players in the field of fashion are increasing. The textile industry as a source of raw materials for the fashion industry has also developed. High production processes leave waste, in the form of chemical waste as well as fabric waste. This fabric waste requires proper handling so as not to pollute the environment. Clothing brands and labels always release the latest designs every season.

There are more than 400 billion square meters of fabric produced into clothing in a year where 15 percent of the fabric ends up as waste, it means that 60 billion square meters of fabric being discarded every year (Eve, 2019). As well as stacks of clothes that are not sold or no longer worn increase the amount of fabric waste that is thrown away.

Environmental pollution can be reduced by not throwing cloth or clothing into the disposal. One way is to design clothing patterns that leave no fabric left, ie zero-waste pattern. This clothing pattern is certainly one that can be easily 
made and created even by ordinary people, so the number of clothes purchased and the amount of fabric waste from the sewing process can be reduced.

\section{LITERATURE REVIEW}

Based on White, Frankle, \& Hindle's paradigm in figure 1., the most favored option in industrial fashion is to minimize or prevent the number of waste. Zero-waste is "the process of discarding nothing in the creation of fashion" (Eve, 2019) it is a suitable method to minimize and prevent fashion waste.

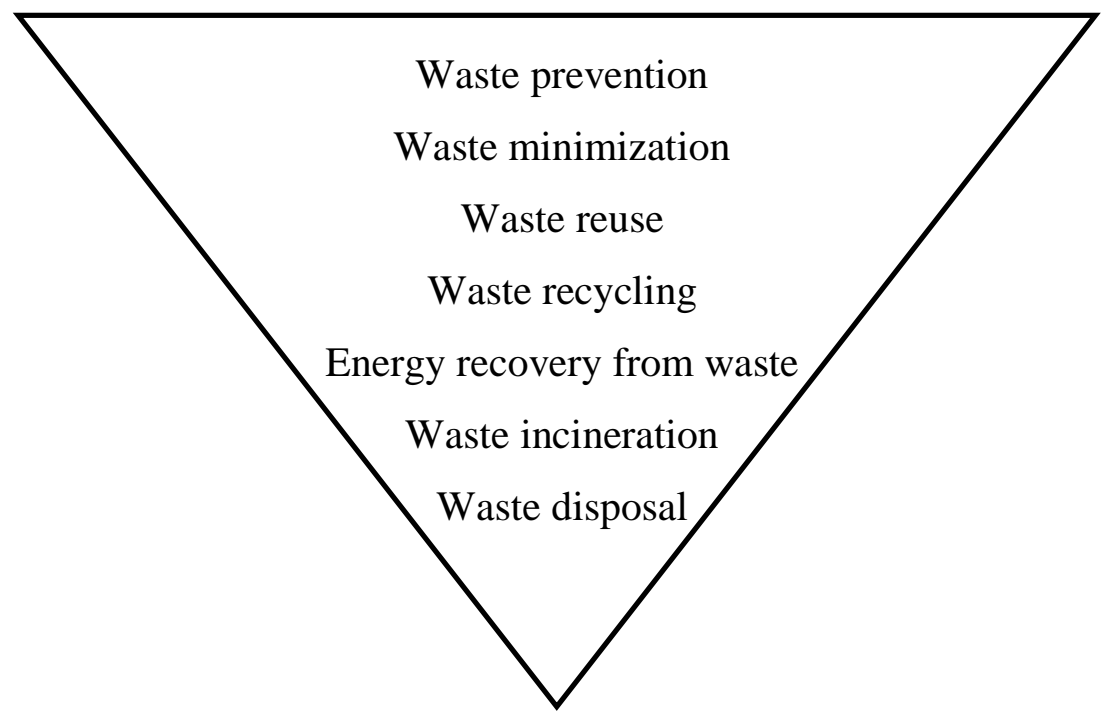

Figure 1. Waste Management Hierarchy, from White, Frankle, \& Hindle’s paradigm (Timo, 2013)

The zero-waste pattern can be found in the figure 2. ie "draped rectangles of uncut / unsewn cloth used in the Greek chiton, and the Egyptian schenti, worn by Tutankhamen; cloth woven to size, then pieces are cut and sewn together for the Japanese kimono" (Gwilt, 2016).
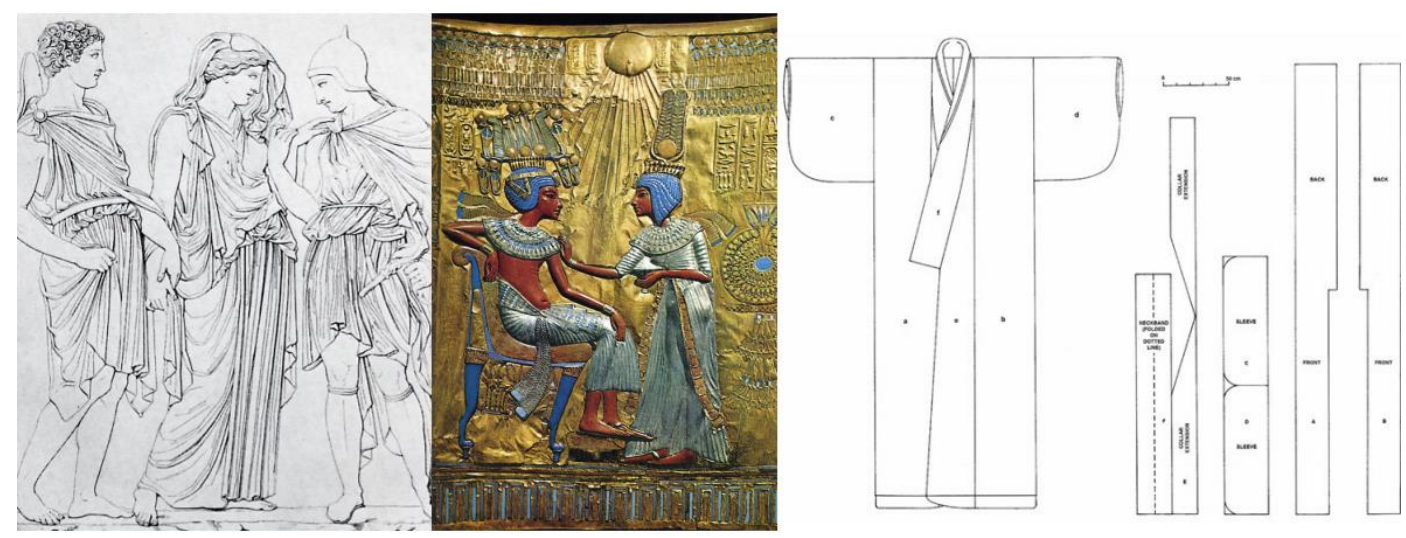

Figure 2. Greek Chiton - Egyptian Schenti - Japanese Kimono (Gwilt, 2016) 
How to make clothes without waste, can be learned from the technique of making Greek chitons that only use fabric without stitches but produce drapes (fabric manipulation) on the finished clothes. We can see one of the creation zerowaste draped from Zandra Rhodes in the early 1970s in figure 3.

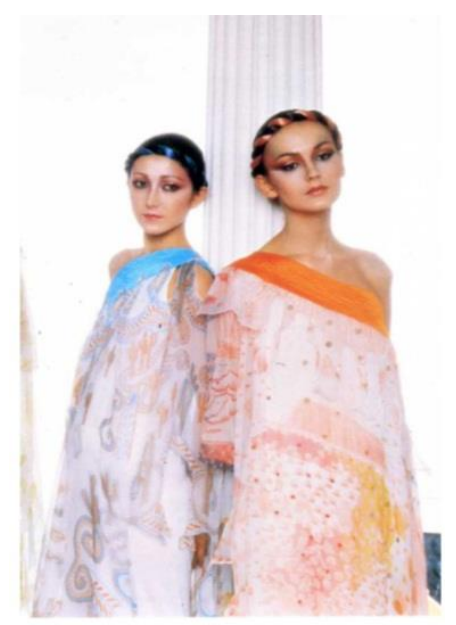

Figure 3. Print And Drape Work (Gwilt, 2016)

We also can make clothes without waste by learning woven techniques (figure 4.) with making woven cloth directly adjusted to the desired size and mode such as clothing designs by "Danish designer, Line Sander Johansen (Kolding School of Design) weaves shaped pieces directly on the loom" (Gwilt, 2016).
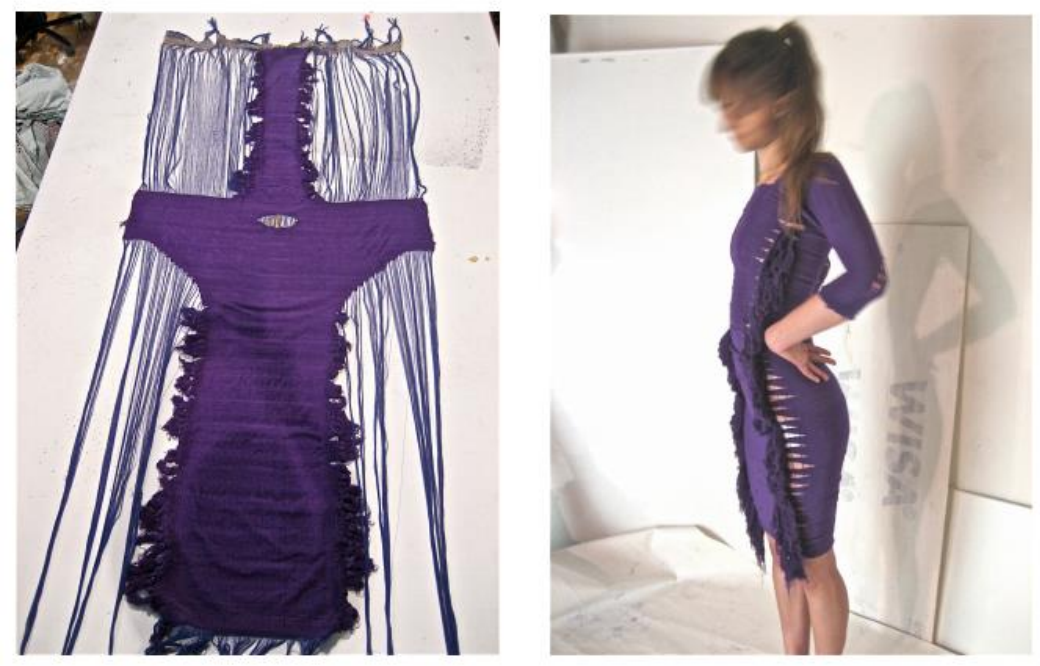

Figure 4. Woven Techniques Zero-waste Pattern (Gwilt, 2016)

This paper examines the development of a zero-waste design pattern based on Japanese Kimono, where the pattern is designed in such a way as to produce sewing that does not leave waste. Like the following work by Yuki and Issey Miyake that first shown in 1970 (figure 5.), Issey Miyake collection of geometric 
garments cut from a single piece of cloth (figure 6.), and David Andersen Copenhagen asymmetry zero-waste pattern (figure 7. )

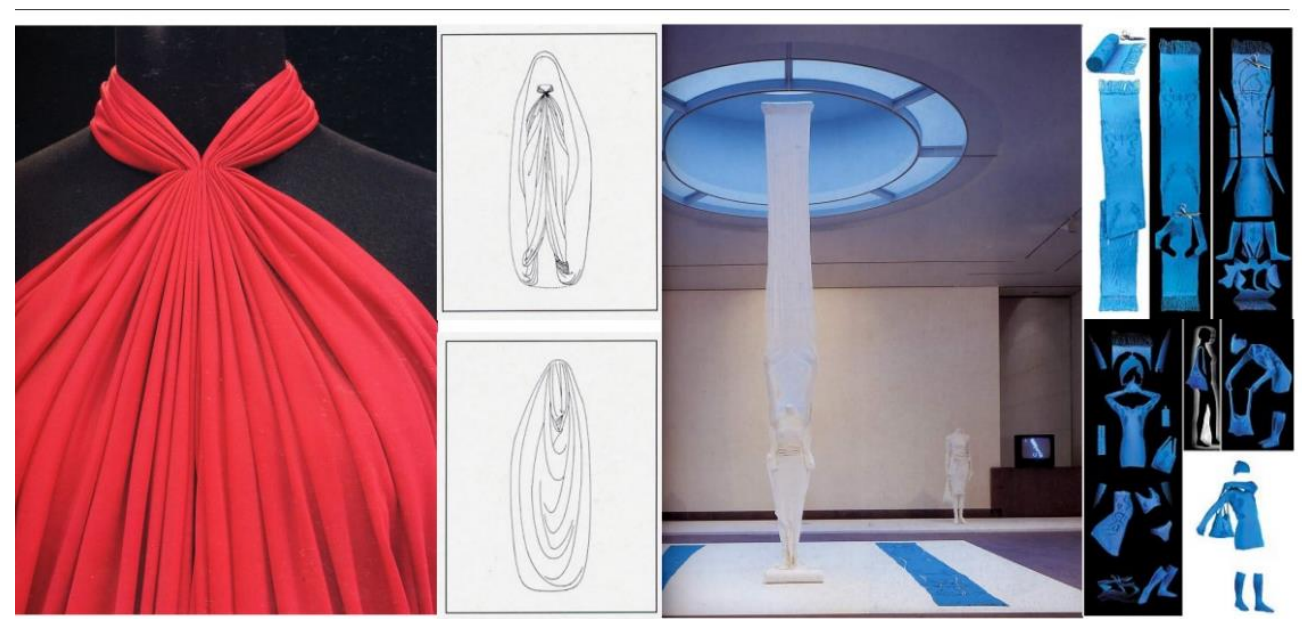

Figure 5. Yuki (red) and Issey Miyake A-POC system (blue) (Gwilt, 2016)

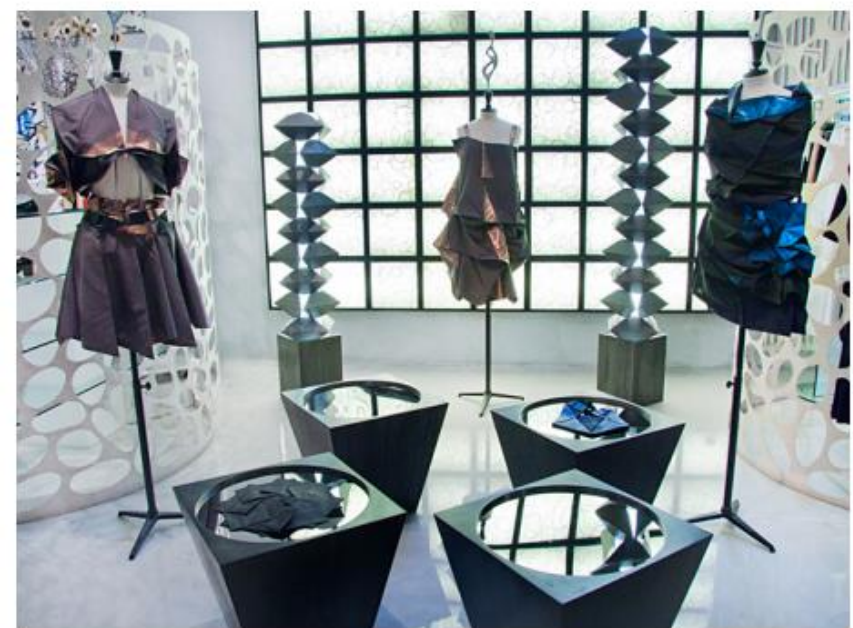

Figure 6.Issey Miyake Collection (Gwilt, 2016) 

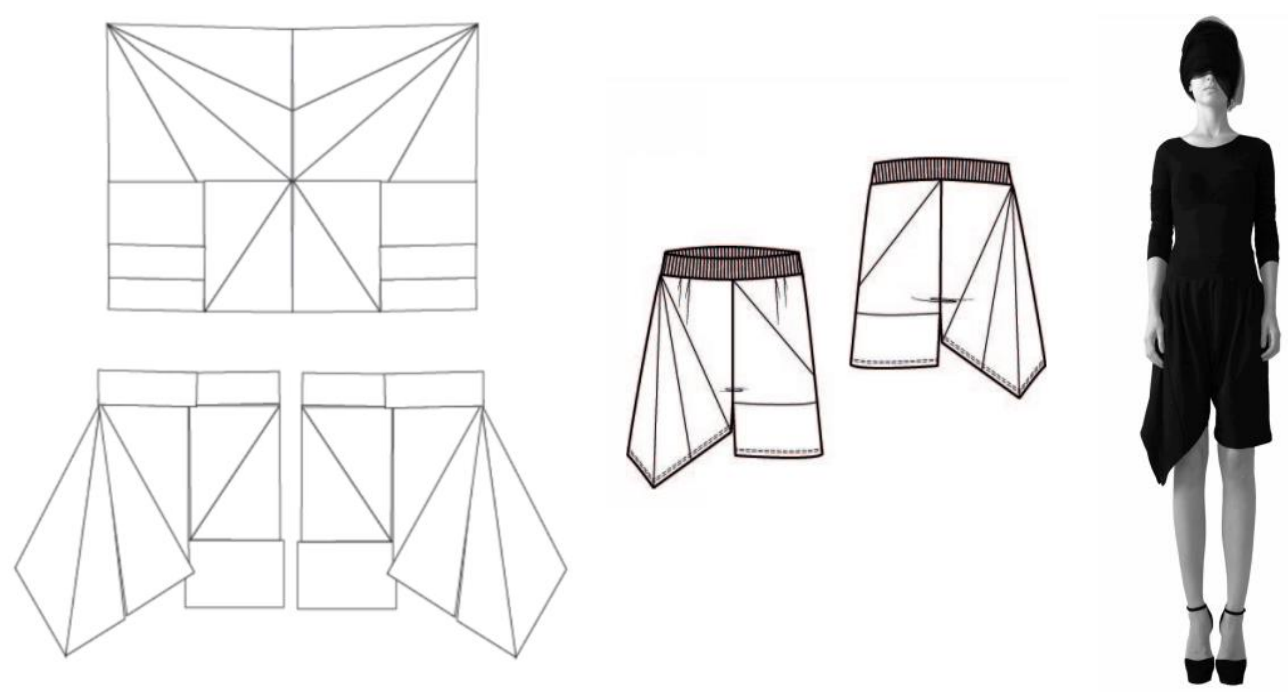

Figure 7. David Andersen Copenhagen SS2013 Zero-waste Range (Gwilt, 2016)

The origin kimono pattern was designed on one sheet of fabric to producing a piece of clothing. While this paper develops clothing with design zero-waste patterns using more than one sheet of fabric motifs to produce clothing. In this study, clothes produced from one main pattern are two modes of clothes. Creativity is needed in developing the outfit, in terms of combining several fabrics and adjusting measurements. "Creativity requires both originality and effectiveness... Original things must be effective to be creative... It may take the form of (and be labeled as) usefulness, fit, or appropriateness..." (Mark \& Garrett, 2012).

\section{METHODOLOGY}

This paper results from research about creativity in zero-waste pattern making. Information about the zero-waste was gathered from the literature study, where the researcher collecting any data from books and make the data as the background research (Fatin, 2017). The practice-based research method also used in this research. Candy, L. \& Edmonds, E. said that Practice-Based Research is a research method for obtaining new knowledge through practice and the results of practices carried out in research, research and practice on this method are interdependent either complement each other.

The author as a researcher conducted a study of literature in advance to gather initial knowledge. The initial knowledge becomes a guideline in conducting practical research until new knowledge is found as a result. Practicebased research was used as a method in doing some experiment in the pattern making.

Data about zero-waste from literature study was found that zero-waste patterns usually make in one fabric become one mode of cloth, but from this practice-based research experiment, there are two modes of cloth from the 
primary pattern in one fabric were produced as a result. The primary pattern can collaborate with another fabric, so the pattern can be developed base on the maker's idea and creativity. There is some pattern that already tested. Two primary patterns will be discussed in this paper.

\section{RESULTS AND DISCUSSION}

These are the two primary patterns: (figure 8.) consists of mode $\mathbf{a} \& \mathbf{b}$ and (figure 11.) consist of mode $\mathbf{c} \& \mathbf{d}$ so there are four modes. Figures $9,10,12$, and 13 are the additional decoration for the primary pattern. These additional decorations can be made with a different combination of fabric. Creativity with originality dan effectiveness is needed here.

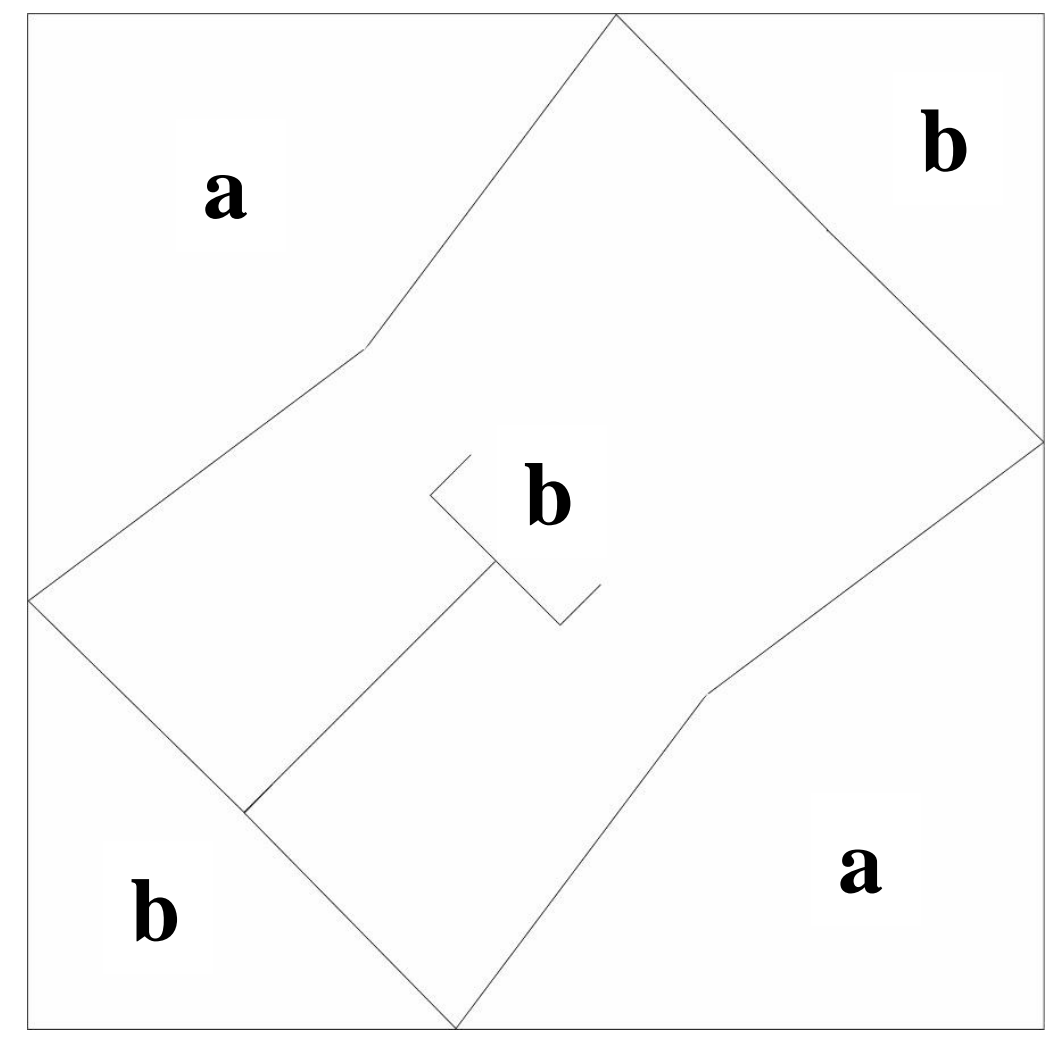

Figure 8. Pattern Primary 1: consist of mode $\mathbf{a}$ and $\mathbf{b}$

Mode a is a pattern for make sleeve, the pattern for body is using the additional decoration in figure 9 . We can choose different fabrics in making the body. Mode $\mathbf{b}$ is a pattern for making the upper body and sleeve, pattern for the lower body is use the additional decoration in figure 10 . 


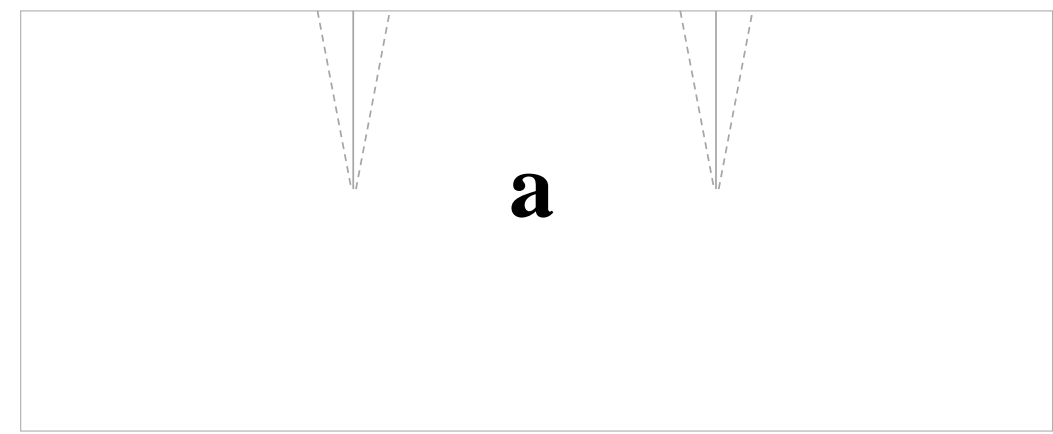

Figure 9. The Additional Decoration for mode a

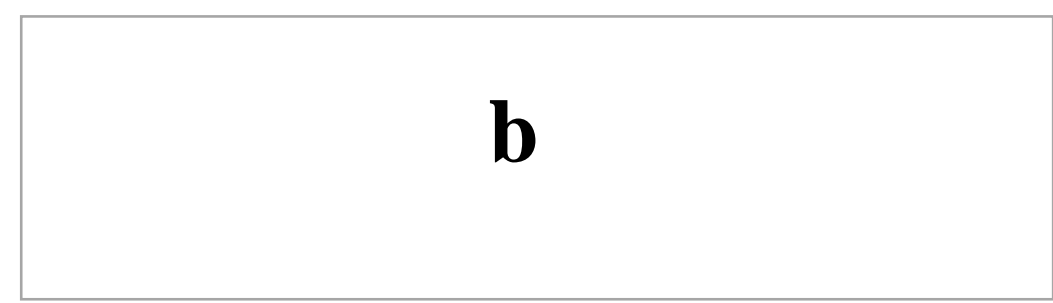

Figure 10. The Additional Decoration for mode $\mathbf{b}$

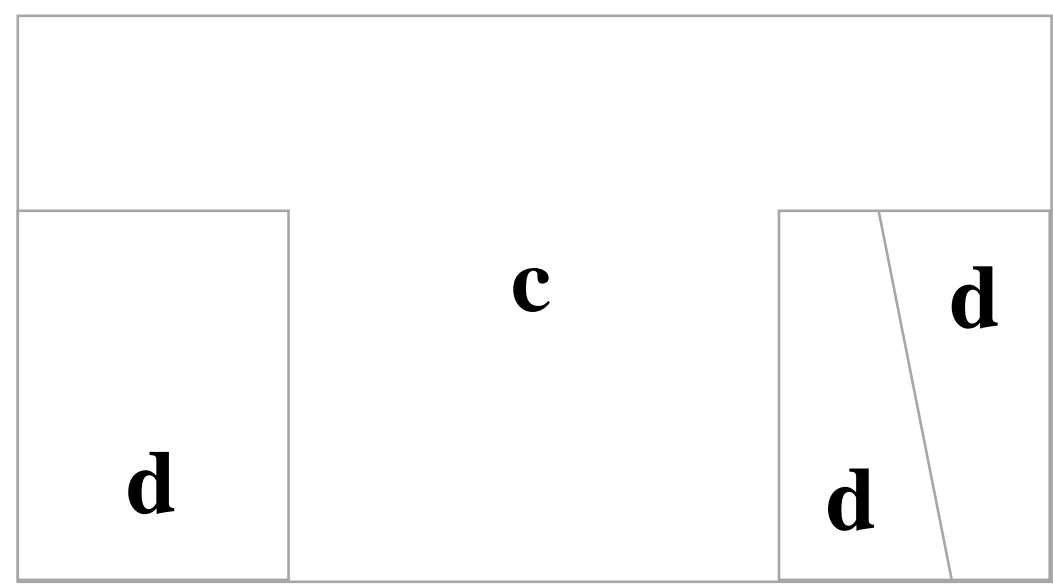

Figure 11. Pattern Primary 2: consist of mode $\mathbf{c}$ and $\mathbf{d}$

Mode $\mathbf{c}$ and $\mathbf{d}$ are patterns without sleeve. The additional decoration for mode $\mathbf{c}$ is collar pattern in figure 12 and for mode $\mathbf{d}$, the decoration is an additional lower body for longer style pattern in figure 13 .

\section{$\mathbf{C}$}

Figure 12. The Additional Decoration for mode c 


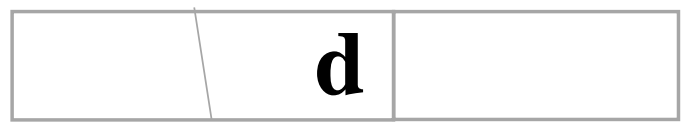

Figure 13. The Additional Decoration for mode d

Figure 14-17 is clothing as a result of the pattern. Shibori and Batik were used in the embodiment of the pattern.

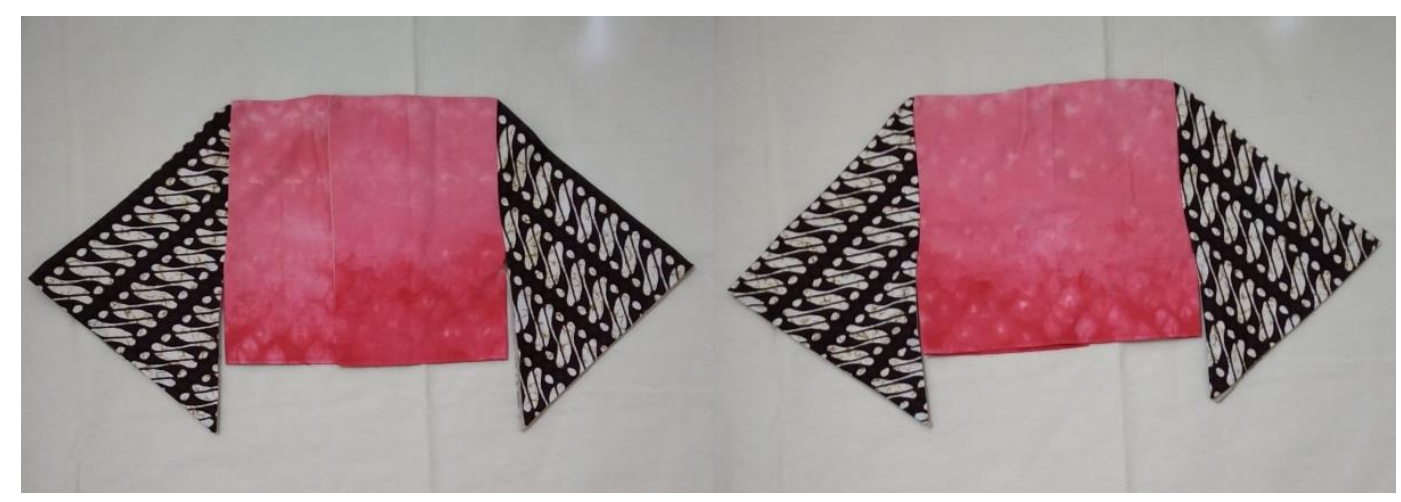

Figure 14. Mode a Front and Back

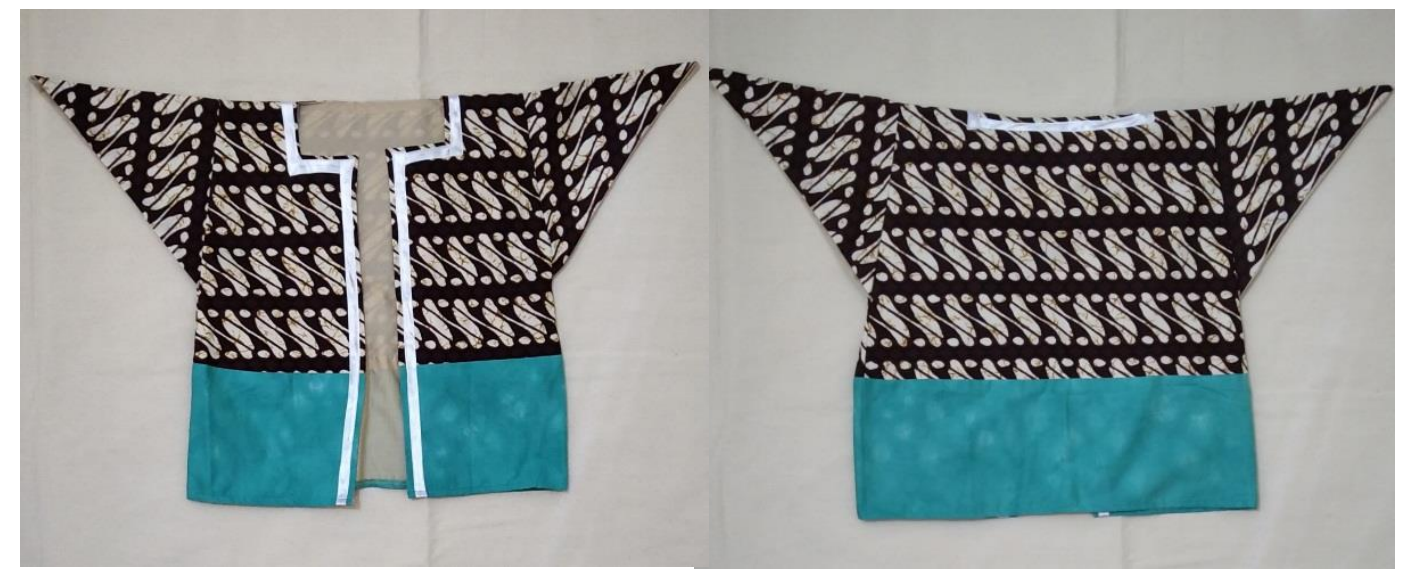

Figure 15. Mode b Front and Back 


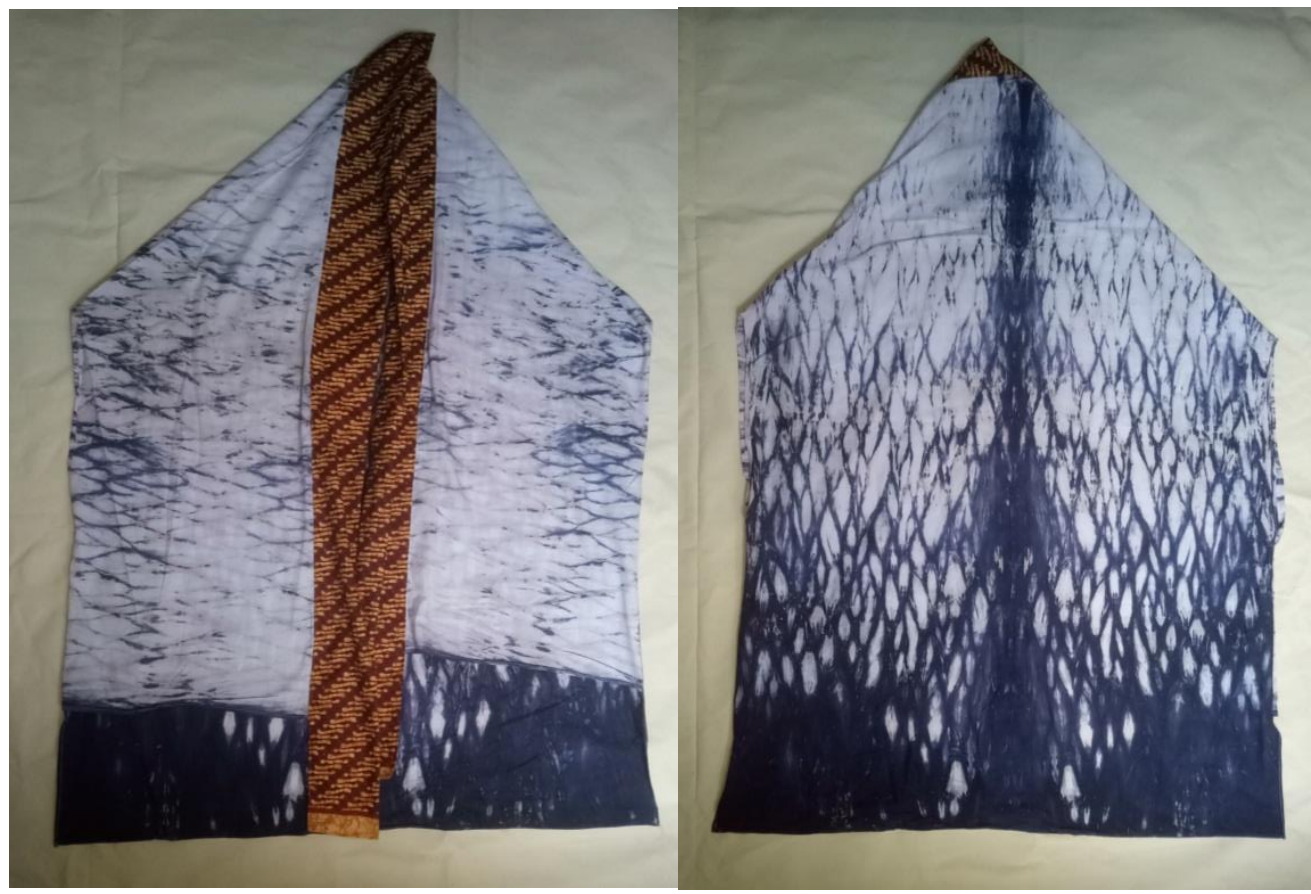

Figure 16. Mode $\mathbf{c}$ Front and Back
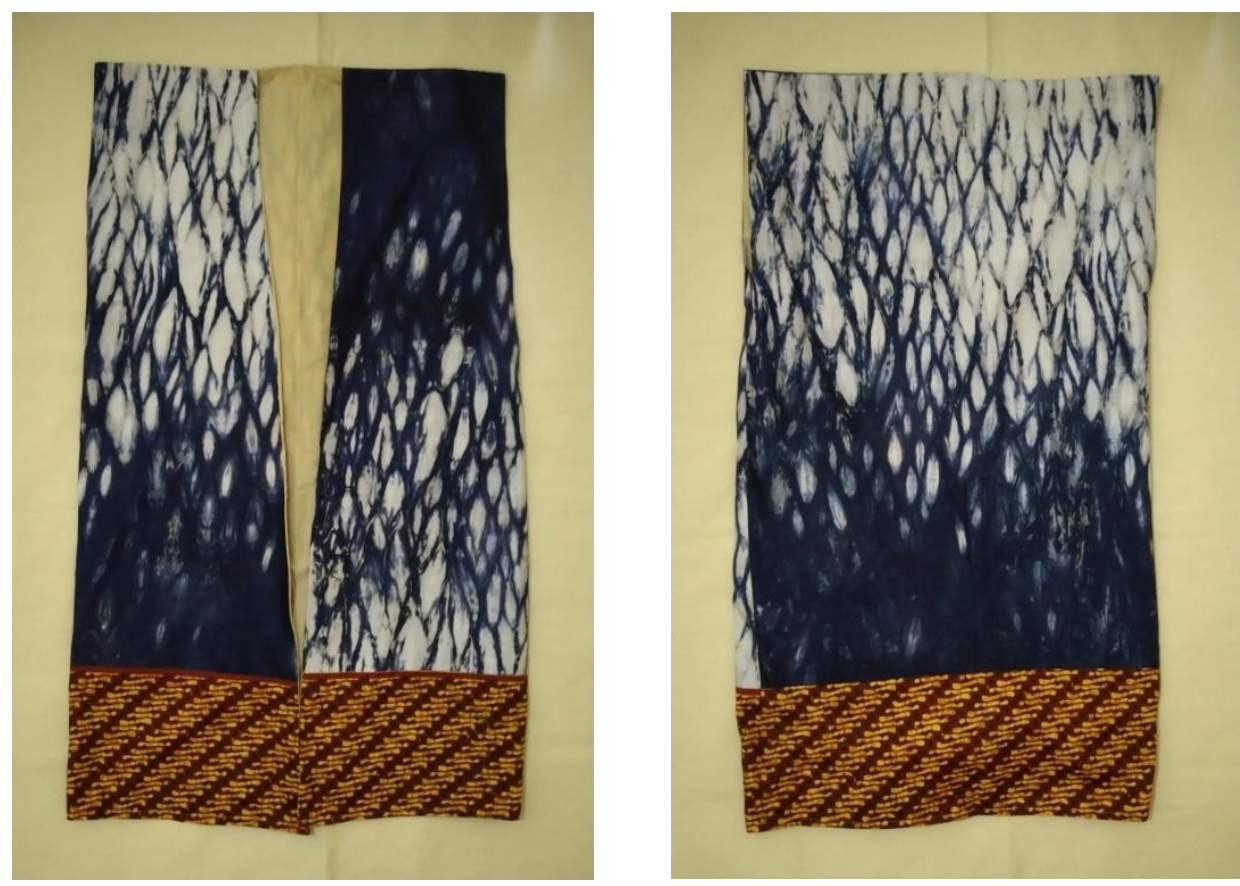

Figure 17. Mode d Front and Back 

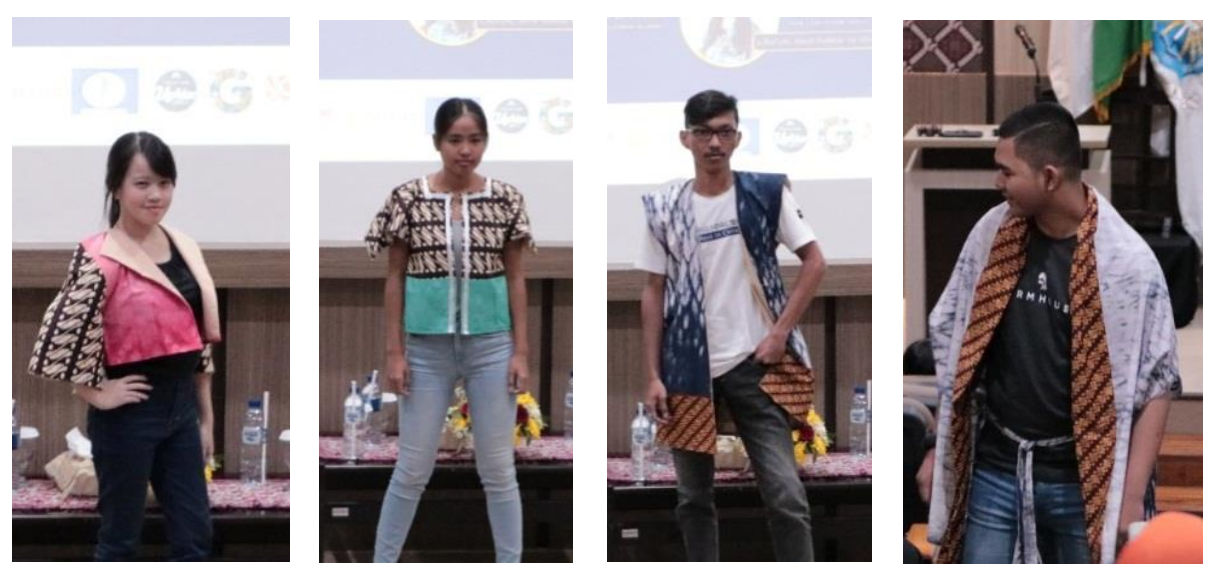

Figure 18. Mode a, b, c, and $\mathbf{d}$ in The Catwalk September 2019

Figure 18 is the documentation where the result of zero-waste pattern mode $\mathbf{a}, \mathbf{b}$, $\mathbf{c}$, and $\mathbf{d}$ were showed in the catwalk. It is seen that all the primary patterns are the zero-waste pattern for making an outer, but this pattern is flexible. to make it become a closed shirt or dress, the maker can adjust the length and width of the desired pattern. This pattern can be made with different measurements to be a different functional pattern, of course, the proper measurement with creativity will affect the result.

\section{CONCLUSION}

Creativity is needed to develop a variety of zero-waste patterns, with creativity, both of the primary patterns above can design and decorate more. Further research should design a more up to date and stylish zero-waste pattern. Fabric manipulation should be used in making the pattern fit to the body.

\section{ACKNOWLEDGMENT}

The author would like to thank Architecture and Design Faculty, Product Design Department, DWCU, Yogyakarta for the funding of this research.

\section{BIODATA}

Centaury Harjani is an Assistant Professor of Product Design Dept on Architecture and Design Faculty from Duta Wacana Christian University, Yogyakarta, Indonesia. She has researches interest in design, fashion, toys, and kids. 


\section{REFERENCES}

Candy, L., \& Edmonds, E. (2018). Practice-Based Research in the Creative Arts: Foundations and Futures from the Front Line. Leonardo, 15(1), 63-69.

Fatin, N. (2017). Pengertian Studi Literatur. Retrieved September 1, 2019, from http://seputarpengertian.blogspot.com/2017/09/pengertian-studiliteratur.html?m=1

Gwilt, Allison. (2016). Zero Waste Fashion Design: Approaches and strategies to reduce textile waste. Sheffield Halam University. UK.

Rissanen, Timo. (2013). Zero-Waste Fashion Design: a study at the intersection of cloth, fashion design and pattern cutting. Disertasi. Design. University of Technology Sydney.

Runco, Mark A. and Garret J.Jaeger. (2012). The Standard Definition of Creativity. Creativity Research Journal, 24(1),92-96.

Tokens, Eve. (2019, 6 May). Zero-waste Fashion: Why It Is So Important. https://www.thecreativecurator.com/zero-waste-fashion/. 30 October 2019. 